\title{
Biological Treatment of Restaurant Wastewater and Diversity of Bacterial Consortium in Bioreactor by Sequencing of 16SrRNA
}

\author{
S M SHAMSUL HUdA ${ }^{1}$, PIYA DUTTA ${ }^{1}$, SUDIPRA DUTTA ${ }^{1}$, \\ AND TANIM JABID HOSSAIN ${ }^{2}$ \\ ${ }^{1}$ Institute of Forestry and Environmental Sciences, University \\ of Chittagong, Chittagong 4331, Bangladesh. \\ ${ }^{2}$ Department of Biochemistry and Molecular Biology \\ University of Chittagong, Chittagong 4331, Bangladesh. \\ E-mail address: hudaifescu@yahoo.com
}

Restaurant, one of the potential small business establishments are increasing rapidly in developing countries like Bangladesh. Every day a huge amount of wastewater is directly discharging to the open drains or canals which ultimately pollute the receiving water bodies as well as groundwater. The present study aims to treat restaurant wastewater biologically and also to investigate the diversity of the microbial community in bioreactor. The study was conducted in the laboratory and a bench-scale bioreactor of $15 \mathrm{~L}$ was set up by using locally available instruments and operated. We directly collected wastewater from the restaurants located in Chittagong, Bangladesh. The collected organic pollutants under overloading condition was fed to activated sludge and incubated for 7-8 hours under aerobic condition by air bubbling for. As the main indicator of the organic contamination measurement is Chemical Oxygen Demand (COD) or Biochemical Oxygen Demand (BOD), we closely observed the COD reduction rate with other related parameters. The microbial population bioreactor was monitored by sequencing of 16S rRNA. The taxonomic classification of the bacteria based on their 16S rRNA Gene was confirmed by the Ribosomal Database Project (RDP) Classifier. In the bioreactor, the reduction efficiency for COD was observed $75-95 \%$ where as TS reduction was 88 $98 \%$. The outcomes demonstrated that the bioreactor is working efficiently for restaurant wastewater treatment. To identify the bacteria present in the sample, various dilutions of the sample were spread on agar plates and five bacteria belong to three different genera namely Bacillus,

Staphylococcus and Pseudomonas were isolated. Almost all the isolated bacteria showed more than $95 \%$ sequence similarity with the sequences in GenBank database. The identified bacterial consortium was effective in removing organic matters from the wastewater. 